\title{
A Baseline Strategy for Human Mars Mission
}

\author{
Malaya Kumar Biswal M*, Devika S Kumar ${ }^{\dagger}$, Vishnu $\mathrm{S}^{\ddagger}$, Sairam $\mathbf{M}^{\S}$ \\ Pondicherry University, Kalapet, Puducherry, India - 605014
}

This paper discusses the baseline mission strategies required for the execution of the Human Mars mission for referral studies. There are many conceptual approaches for the consideration and enhancement of current mission strategies. Additionally, this paper overviews the entire aspects of permanent human settlement on Mars. The whole mission was technically discussed with three distinct phases. A blueprint of the overall Mars base foundation was displayed and extended a novel approach towards the development of the interplanetary communication system.

\section{Nomenclature}

$\begin{array}{ll}B F R & =\text { Big Falcon Rocket } \\ E D L & =\text { Entry, Descent, and Landing } \\ H I A D & =\text { Hypersonic Inflatable Aerodynamic Decelerator } \\ I M S & =\text { International Mars Station } \\ I S R U & =\text { In-Situ Resource Utilization } \\ \text { LEO } & =\text { Low Earth Orbit } \\ \text { LSSM } & =\text { Life Support System Module } \\ M A V & =\text { Mars Ascent Vehicle } \\ M C C S & =\text { Mars Crop Culture System } \\ M L R & =\text { Mars Load Rover } \\ M M C S & =\text { Mars Master Control Station } \\ M M H & =\text { Mono Methyl Hydrazine } \\ M P R & =\text { Mars Passenger Rover } \\ M S A F & =\text { Mars Security Armed Forces } \\ M S F R & =\text { Mars Soil Fertilizing Rover } \\ M S L & =\text { Mars Science Laboratory } \\ M S P P & =\text { Mars Solar Power Plant } \\ M S S H & =\text { Mars Sub-Surface Habitat } \\ N A S A & =\text { National Aeronautics Space Administration } \\ P S H & =\text { Planetary Surface Habitat } \\ S C R S & =\text { Solar Cell Radiation Shield } \\ S F M & =\text { Space Farming Module }\end{array}$

\section{Introduction}

In this paper, we have represented possible methods and technology to execute the human class Mars mission and establishment of Mars Base (Mars City). We have displayed a blueprint of the whole Mars Base on the second page. As per our strategy, we have classified the whole mission into three distinct phases from launch to the colonization shown on the third page. We have extended our novel approach to spaceship designs, efficient interplanetary communication systems, anti-dust deployable solar panels, Mars sub-surface habitats for the protection against dust storms and thermal regulation, integrated solar cell radiation shield and resource enhancing fertilizing rovers and exploiting vehicles.

\footnotetext{
* Graduate Researcher, Department of Physics, School of Physical, Chemical, and Applied Sciences, Pondicherry University, Kalapet, Puducherry, India; Member of Indian Science Congress Association, Student Member AIAA. Corresponding author: malaykumar1997@gmail.com.

$\dagger$ Graduate Researcher, Department of Earth Sciences, Pondicherry University, Kalapet, Puducherry, India. devikask412@ gmail.com

‡ Graduate UI/UX Designer, Department of Computer Science, Pondicherry University, Kalapet, Puducherry, India. vishnucse57@ gmail.com

${ }^{\S}$ Graduate Researcher, Department of Mechanical Engineering, Pondicherry University, Kalapet, Puducherry, India. sairamsiva198@ gmail.com
} 


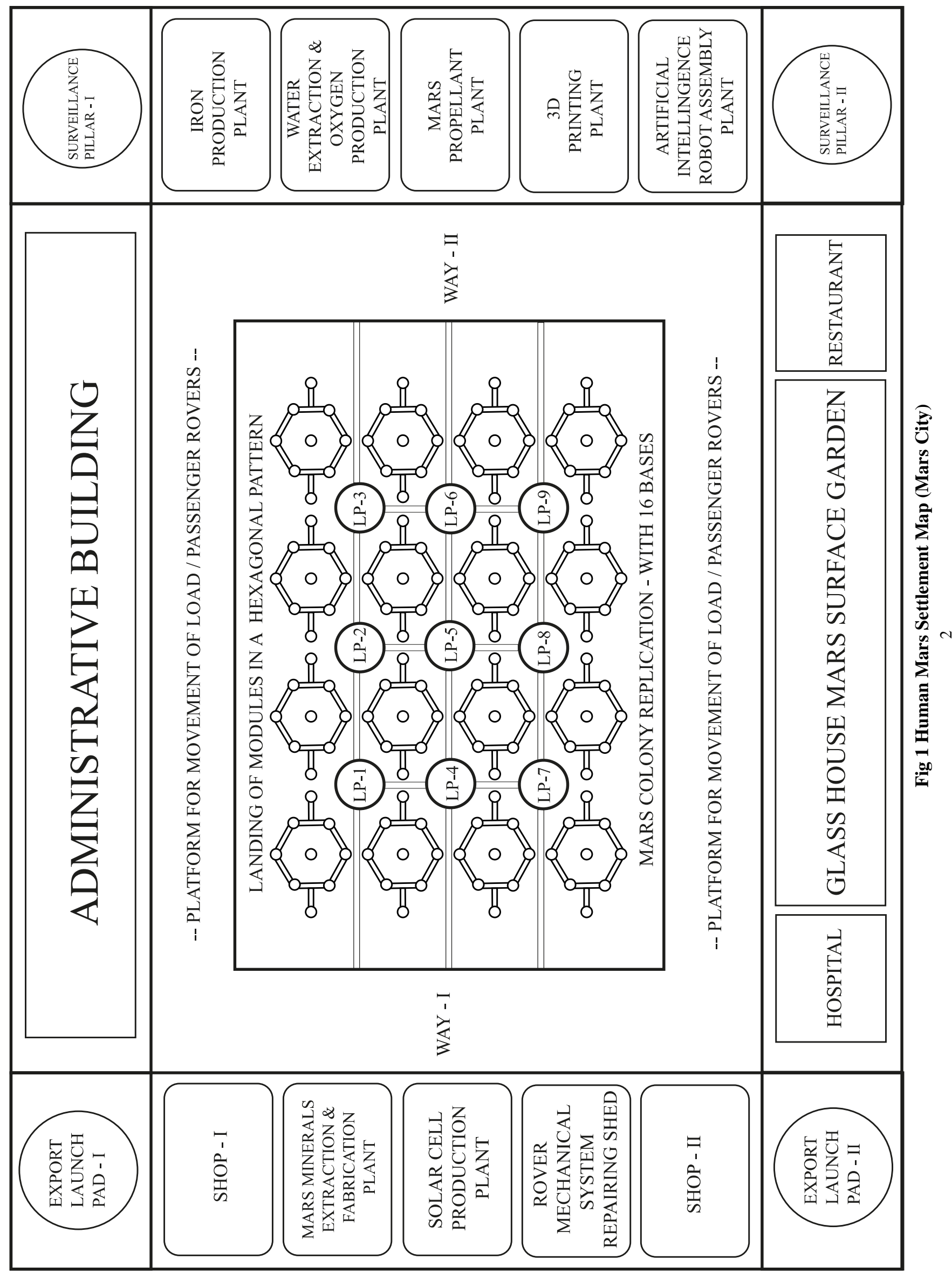




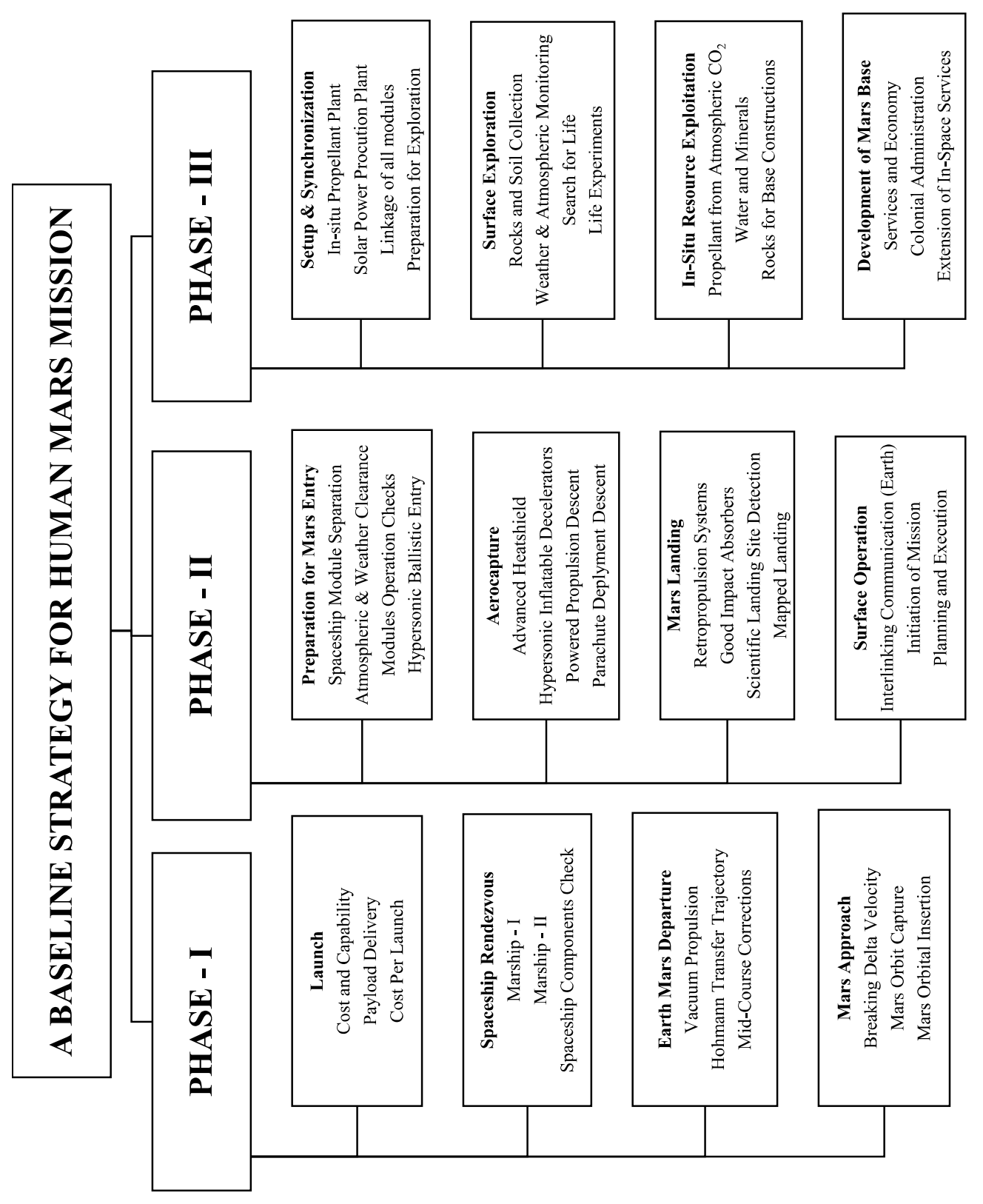




\section{Technology Considered}

\section{A. Technology Considered in this paper}

- Heavy Lift Launch Vehicle

- Dual Communication Systems

- Anti-dust Deployable Solar Panel

- Mars Sub-Surface Habitat

- Sub-surface Ice Drillers

- Auto-Cropping and Atmosphere Regulation System

- Automated Soil Fertilizing Rover

- Integrated Solar Cell Radiation Shield

- Retractable and Deployable Solar Panel Case

- Conveyer Belt Roving Vehicles

- International Mars Station

- Auto Trajectory Correction Maneuvering System

- Automated Scientific Landing Site Detection and Landing System

- Rapid growing plants for faster food production

- In-Situ Resource Utilization

\section{Mission Phase-I}

\section{A. Launch}

In the present-day scenario, the human class Mars mission requires heavy-lift launch vehicles capable of delivering large payload masses into low earth orbit and to the Mars transfer orbit. Looking into our current trend of technology, we have chosen the Starship (BFR Previous version) or its equivalent Falcon Heavy Expandable and Delta IV Heavy. It is because these launch vehicles are capable of delivering heaviest mass up to 100 tons to 150 tons into LEO. Hence, for our Marship assembly and rendezvous, we propose to launch and deliver all the payloads aboard this launch vehicle in two round attempts.

\section{Attempt-I}

In this attempt (2-3 Starship launches) Starships will be launched carrying the Marship segments like cargo module, fuel tanks (fueled), crewed module, life support systems, medical module, and Mars Ascent Vehicles-I for the assembly of Marship-I (with autonomous rendezvous technology).

\section{Attempt-II}

In this attempt (2-3 Starship launches) Starships will be delivering the cargo module, Mars Landers \& Rovers, Mars Habitat I \& II, and Mars Ascent Vehicle-II for the assembly of the second spaceship called Marship-II (with autonomous rendezvous and technology).

\section{B. Spaceship Rendezvous}

Spaceship modules stranded in LEO will start its operation of autonomous rendezvous to form integrated Marship-I \& II. The Marships will be assembled in the following order shown below in a block diagram. 
Marship - I Assembly Order

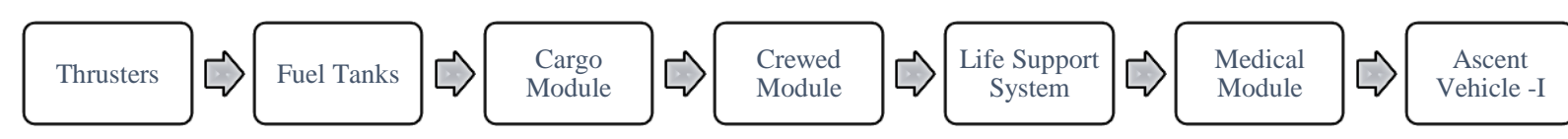

Marship - II Assembly Order

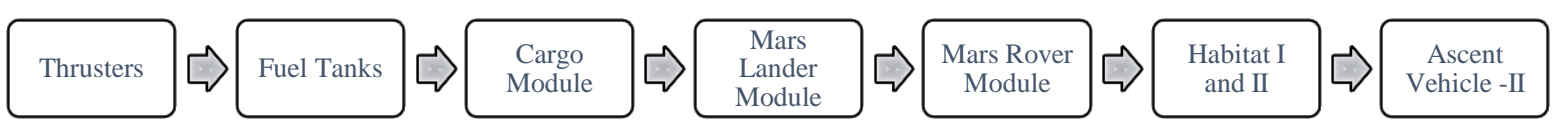

Figure 2 Block Diagram of Marship Rendezvous

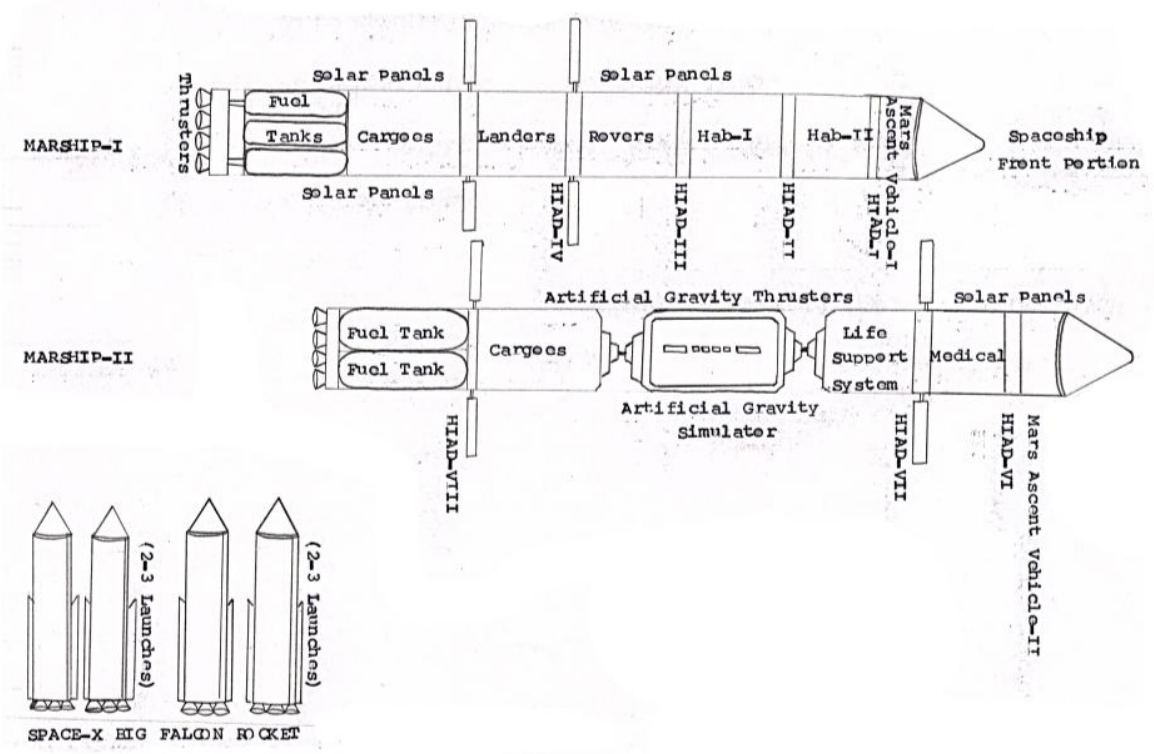

Figure 3 Spaceship Rendezvous (Marship I \& II)

\section{Features and Segments of Spaceships}

Thrusters: We propose to use monopropellant thrusters to drive and propel the spaceship. Because it is still uncertain and unproven that ion or electric in-space propulsion thrusters are capable of driving huge spaceships. We know that monopropellant or chemical rockets have a low specific impulse and can produce minimal delta velocity of 4 to 5 $\mathrm{km} / \mathrm{sec}$ required to follow minimal energy trajectory from Earth to Mars using Hohmann's conjunction class TransMars Trajectory. And this minimum delta velocity is optimum and no opposition propulsion required during Mars orbital insertion to cut down the velocity of the spaceship.

Fuel Tanks: Fuel tank is filled with MMH (monomethyl hydrazine or hydrazine) for the in-space propulsion system. The fuel tank we installed here is customizable and reusable for crop culture after usage.

Lander Module: Lander module consists of scientific equipment, scientific laboratories sets, and other miscellaneous materials or tools for surface exploration of Mars.

Rover Module: Rover Module encloses Water extraction rover for Mars sub-surface water extraction, surface mobility rovers for astronauts to move from their base to a scientific exploration site, cargo loaders to carry raw materials from resource location to construction site and science mission rovers for the application of surface exploration and detection of resource-rich zones. 
Habitat - I and II: Mars Habitats provides living spaces and necessities for the survival of Martian astronauts on the surface of Mars.

Mars Ascent Vehicles (MAV - I \& II): These vehicles are optional and can be utilized in case of return trip back to Earth, or else in the future, it can be alternatively employed for traveling and accessing International Mars Station stranded in Mars orbit.

Crewed Module: Crewed Module provides a comfortable living space for carrying a large number of people for permanent Mars settlement. Our crewed module is a conceptual model and can carry more than 100 astronauts to Mars. Its effective structure and design are shown in Fig 5. Additionally, this module possesses AG (Artificial Gravity) Thrusters to simulate artificial gravity essential for a low-gravity environment and is one of the significant challenges for human class missions. Further, we propose to dock a crop culture module in a perpendicular direction to this module for better sunlight exposure. And the crewed module will provide artificial gravity for the healthier growth of space plants.

Life Support System Module (LSSM): It holds a space for the growth of green plants under solar-powered artificial light. This module is included for the enhancement of the Carbon-Oxygen $\left(\mathrm{CO}_{2}-\mathrm{O}_{2}\right)$ cycle between the crew and the plants.

\section{Earth-Mars - Trans-Mars Transit:}

After spaceship rendezvous, all the modules and their operations are well checked in advance for prosperous interplanetary spaceflight. Then the Marship moves and propels towards Mars using high powered propulsion thrusters over Hohmann's Transfer trajectory. All the operating electrical components and electrical systems are powered by high powered Solar cells. The crewed module of Marship - I is capable of generating artificial gravity and employs it during interplanetary spaceflight to compensate zero-gravity environment.

\section{E. Mars Approach}

After a long cruise of interplanetary spaceflight of approximately 270-300 days, the spaceship finally approaches Mars. And the delta velocity is optimum and does not require any opposition propulsion for Mars orbit capture or Mars orbital insertion.

\section{Mission Phase-II}

\section{A. Preparation for Mars Atmospheric Entry}

Following Mars Approach, all the modules of Marship I and Marship II get separated as shown in Fig 4. Before performing hypersonic ballistic atmospheric entry, overall component systems and their communication links were checked and validated in advance. Additionally, their communication systems were interlinked with either International Mars Station or Mars Master Control Station for uninterrupted signal processing during effective landing operations. Furthermore, atmospheric and weather clearance are broadcasted in advance from Mars orbiters (Mars mappers) and surface exploration rovers and landers. These follow entry from orbit which is considered to be the safest approach for EDL systems.

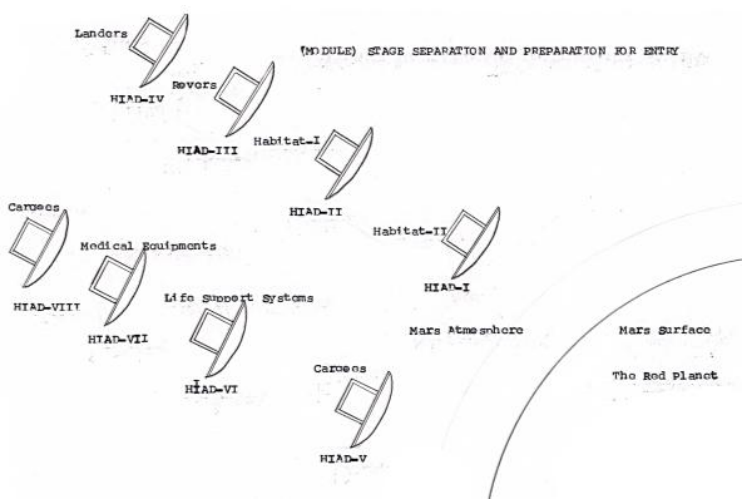

Fig 4 Preparation for Mars Atmospheric Entry 


\section{B. Aerocapture}

All the modules will perform hypersonic entry followed by rapid aerodynamic deceleration with the aid of HIAD. Because all the modules are exposed to atmospheric heating due to the thickness of the atmosphere. Hence, we have incorporated a double-layer heat shield (i.e., standard heat shield having extra water layered coat). This may effectuate good heat resistance and protection thereby contaminating the Mars atmosphere with a small quantity of water vapor. Electively, we have packed the modules with large sized parachute deployment systems along with powered propulsion systems (retrorocket) for performing effective soft-landing.

\section{Landing}

Aerocapture is followed by a safe and effective landing operation. Modules get landed as per the site allocated in advance as shown in Fig 1. Every lander possesses a good impact absorbing system and automated landing site detection for performing precision landing.

\section{Surface Exploration}

Cosmonauts from the crewed module (future Martians) will undergo a discussion from the perspective of current and future surface exploration planning. The discussion includes what and how to exploit the resources for good colonial development.

\section{Mission Phase-III}

\section{A. Setup and Synchronization}

Landed modules were interlinked with solar power plants and the communication system is paired with either International Mars Station or Mars Master Control Station stranded in Mars orbit. Setting up of modules follows fixture of solar power plant for massive power generation; water extraction plant for producing planetary resource water; crop culture system for production of food grains for survival needs; in-situ Mars propellant plant for the production of methane - Martian propellant for ascent and descent applications; $\mathrm{CO}_{2}$ (Carbon dioxide) - $\mathrm{O}_{2}$ (Oxygen) cycle enhancement plant for generation of free oxygen for astronauts and management of exiled $\mathrm{CO}_{2}$ gases; establishment of surveillance copters to monitor space activities and asteroid detection. Finally, mission strategy and scientific goal accomplishment are initiated.

\section{B. Mars Surface Exploration Strategy}

- Investigating the collected samples of surface rocks \& soils

- Continual monitoring of atmospheric weather conditions

- Searching and detecting the location of mineral-rich resources

- Reporting and forecasting the atmospheric changes

- Tracking of asteroids (based on their counts and impact on the surface)

- Search for the existence of past evidence for life

- Locating dead missions and analyzing the stacked results (due to inability in transmission)

- Repeated experiments on life creation and adaptation concerning Mars environmental conditions.

- Training the life to adapt to the gravity of Mars and its environmental conditions.

\section{In-Situ Resource Utilization (ISRU)}

- Massive production and exploitation of Martian propellant

- Extraction of sub-surface ice and transforming into consumable water for practical applications.

- Utilizing rocks for the construction of bases and other minerals for the fabrication of useful equipment and other useful applications.

- Recycling of Martian minerals described in table 1. For the fabrication of useful components, apparatus, or conventional needs. 


\section{Mars Colony Replication}

Adequate tests and validated artificial intelligence robots may be exported from Earth in the future for the construction of advanced Mars bases. Gradually, the constructed base will replicate over the years to form a Mars City for permanent Human Mars Settlement.

\section{E. Regular Mars Assignment}

- Every Martian should pledge for the prosperous development of the Martian community in terms of technology and survivability.

- Every Martian should go for scientific research and exploration in favor of fulfilling their essential needs to keep the stableness of their mindset and interest over Mars's survival challenge. So that the community will grow expeditiously without any divergence and self-esteem among Martians. And they should work in cooperation.

- Before entering into the regular assignment, everyone is suspected to have equipment's and appliances validated. Similarly, all these apparatuses should undergo maintenance after completion of work. Because new instruments cannot be imported back from the earth at a regular frequency.

- Safety and Security is the ultimate key to avoid extinction of the Martian community. Hence few groups of people are always assigned to monitor atmospheric weather conditions and to track the asteroid impacts onto the surface.

- Despite several survival challenges, Martians are advised to do physical exercise to make them healthy and fit in a low gravity environment.

- The last and most significant point is, there should not be any dissimilarity between people working under cooperation from various nations. And they should be commonly called "The Martians".

\section{F. Recommendations for the Economic Prosperity of Mars Colony}

- Selling the rock and soil samples to the developing nation (Nations attempting to reach Mars)

- Commission of In-Space Servicing Missions (i.e., repairing and restoring the dead or malfunctioned spacecrafts orbiting around the red planet, with the aid of "Autonomous rendezvous capturing system \& servicing Module".

- Extending our escorts and hospitality services to the forthcoming astronauts from Earth (who had arrived for the intent of executing research works or space tourism) via International Mars Station for astronauts in Mars orbit and Mars Guest Apartments for the astronauts landed on the surface in exchange for money.

- Developing the red planet, a platform for Interplanetary and Deep Space Network by constructing and setting up of large-sized antennas to provide powerful Inter-Space communication relay between the Earth and the spacecrafts/spaceships voyaging beyond Mars for the financial benefits.

- Expanding the Martian technology to make available "In-Space Emergency Mission" in case of critical calamity or interplanetary assist to the cosmonauts voyaging from Earth to various space destinations for the interest of money.

- Serving EDL and trajectory guidance for Earth-based Mars landing for sake of money via MMCS from Mars orbit. Because direct control from ground stations on Earth may cause signal interruption and EDL tragedy during blackouts.

- In the future, if we succeed in mass production of In-Situ Mars propellants, the feasibility of In-Space Onorbit Refueling of spaceships/spacecrafts can be commissioned for Deep Space Transportation and TransEarth Transit.

- In forthcoming years, private space agencies whoever wants to buy or establish their base on the red land and wants to be a cooperative member of the Mars colony, they must pay some debts to acquire a license of use to form their bases.

- Extracting and fabricating some useful materials for the application of astronauts can be commercialized for commercial space constructions and serving for the ease of wages. 


\section{G. Administration Approach}

- Mars colony will be administered by officials from every nation under a common body of alliance. And the government will be democratically elected by every individual of the Martian community based on the performance in colonial enhancement and development.

- There should be one base of the army called "Mars Space Armed Forces" for the protection against Space Wars in the future. The MSAF consists of unified armies from overall nations. Supersonic Spaceflight Jets are the major source of war expedition.

\section{Detailed Description of Spaceship Modules}

\section{A. Crewed Module}

The crewed module comprises restaurants, gymnastics, restrooms, discussion rooms, and power \& maintenance room. The middle portion of this unit has a sleeping chamber and a scientific laboratory. Sleeping chamber specially allocated for sleeping aboard sleeping berths. Similarly, a space allocated for performing scientific activities. Here A1 \& A4 were the primary airlocks and A2 \& A3 were secondary airlocks. Here air locks aids in systemizing air and pressure management inside the unit as well as to restrain air-escape. D1 \& D2 were the door locks to enter into the sleeping berths. The door kept here because the sleeping chamber has a temperature regulation system to balance heat and cold during interplanetary spaceflight.

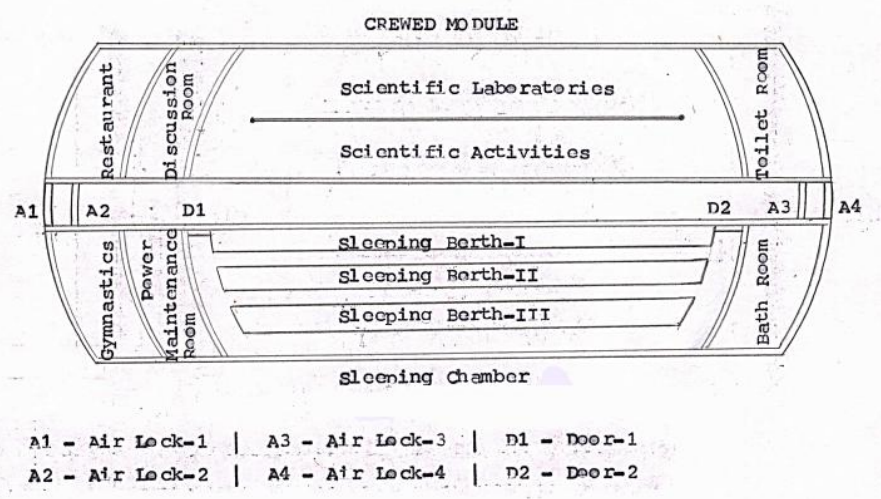

Fig 5 Structure of Crewed Module

Restaurants: Restaurant has lighter and nutrition-rich food items. The food system is followed by the food habits of the International Space Station. The restaurant is efficient to serve Beverages (include coffee, tea, lemonade, and orange drinks), Fresh foods (includes fruits and vegetables grown aboard the spaceship), meats (irradiated meat), moisture-rich foods, natural foods (includes nuts, cookies, waffles, and rolls), condiments (includes liquid salt solution, oily pepper paste, mayonnaise, ketchup, and mustard), and tortillas.

Discussion Room: The room is specially allocated for astronauts convention to make discussion and to instruct them about the mission aspects. This is a multipurpose hall and can be transformed into a playing hall. There is a crystal glass for a spectacular view of space from the sitting position inside this hall.

Gymnastics: It comprises of all equipment to help make cosmonauts fit and healthy. This section is included concerning the health issues encountered in a zero-gravity environment.

Power and Maintenance Room: This unit has control over the power supply to the overall module, and has service tools for the module management. It also holds additional necessities such as oxygen tanks, fire extinguishers, space suits, space ropes, and miscellaneous. 


\section{B. Cargo Module}

In this module, we have divided the whole chamber into ten different cargo counters for the loading and unloading process. Similarly, we have allocated ten narrow passages to provide easy access to available cargoes. This chamber holds cargoes such as preserved food materials, drinking waters, costumes, space suits, propellants, scientific tools, medicinal ingredients, necessities of cosmonauts, and other miscellaneous items. It also possesses a good refrigeration system for the preservation of food items and medicinal constituents. This module also has a power \& maintenance room along with the primary and secondary air-locks.

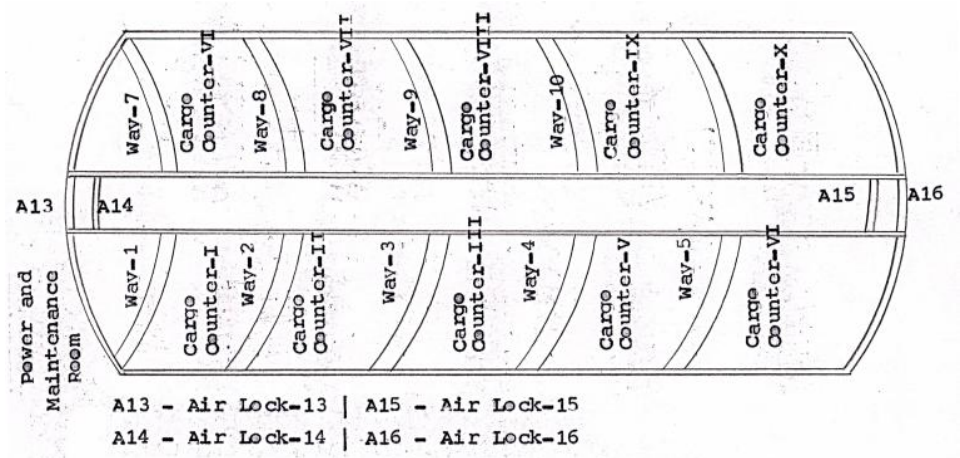

Fig 6 Structure of Cargo Module

\section{Crop Culture Module / Space Farming Module (SFM)}

This module is specially designed and incorporated to Marship for in-space farming to meet food requirements. The prime objective of this module is to provide a self-sufficient and sustainable food source during interplanetary spaceflight. Here we can grow vegetable production and oxygen production plants.

The structure of this module is made like the upper portion of this module is coated with pellucid glass to allow filtered sunlight for the light exposure to the on-growing plants. The lower portion of this chamber is allotted for plantation of food crops, soil maintenance, and food production. The unit is connected to the water and atmosphere regulation chamber for the periodic supplement of water, carbon dioxide, nitrogen, and $\mathrm{CO}_{2}-\mathrm{O}_{2}$ cycle enhancement between the crewed module and crop culture module.

The right corner of this module has room for keeping farming tools and agricultural accessories (includes seeds, saplings, fertilizers, etc.). Similarly, the left corner of this module is allocated for storing and preservation of foods produced from farming. We are intent to dock this module in a perpendicular direction to the crewed module for providing artificial gravity to growing plants to compensate for the effect of zero-gravity on plant growth. This module also possesses primary and secondary air-lock systems.

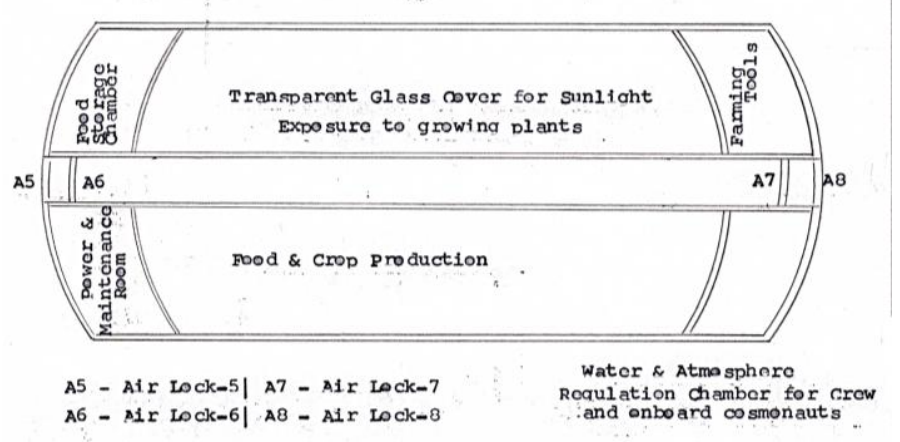

Fig 7 Structure of Crop Culture Module 


\section{Medical Module}

The medical module is incorporated for medical care during interplanetary travel. It comprises advanced treatment apparatus such as radiation dose monitors, surgical instruments, scanning devices, and many other space-based firstaid kits. We have allotted half-central portion of this module for keeping pharmaceuticals and medical equipment, and deep sleep chamber for inducing sleep in case of a larger number of astronauts during space travel. Additionally, special two rooms were allocated at both ends for the medical care and treatment. This cryogenic sleep chamber is synchronized with a cryogenic coolant maintenance room. Like all modules, it also has a power and maintenance room along with primary and secondary air-locks and pressurization systems.

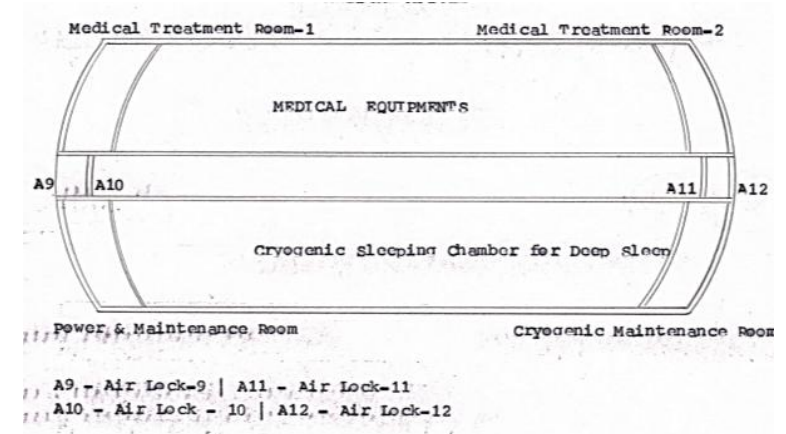

Fig 8 Structure of Medical Module

\section{Overview of Planetary Exploration Technology}

\section{A. Mars Ascent Vehicle (MAV)}

In our architectural design, we have optionally attached two Mars Ascent Vehicles (MAV-I \& II) for space use. They can be either modified and integrated into the main body of the Marship to control and drive during interplanetary spaceflight or it can be employed to ascend from the surface of Mars during any emergency scenario. This vehicle possesses good integrated hydraulic extension legs for frequent landing and ascending applications and also possesses powerful thruster to take off from Mars. It can deliver huge cargo and crew to the Mars orbit.

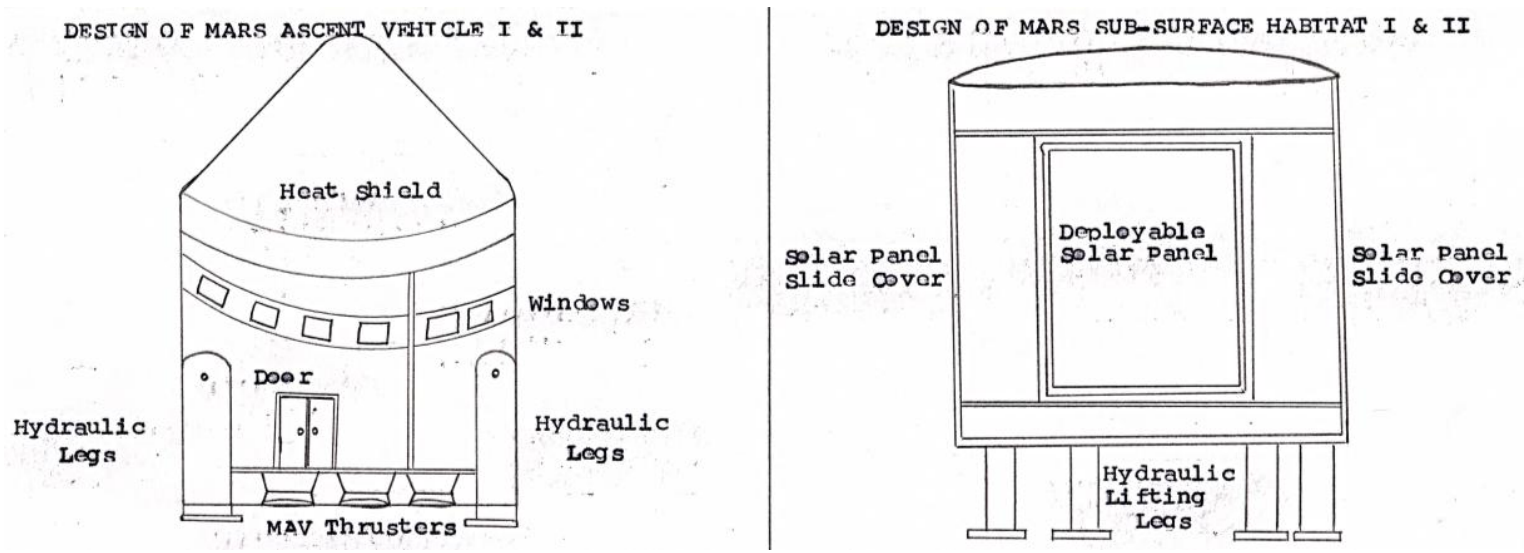

Fig 9 MAV and MSSH

\section{B. Planetary Surface Habitats (PSH)}

We have included two planetary surface habitats (Habitat - II \& II) for providing living space to the cosmonauts on the planetary surface. It is a small home and has all facilities for the survivability. We can see in Fig 9. we have mounted deployable solar panels attached to the habitat. The panel is extensible and dust-proof due to the closet doors. After sunset, the panel will get enclosed and attached to the habitat wall within closet doors. This will protect the solar panels from dust deposition during periodic Martian dust storms. 


\section{Mars Sub-Surface Habitat (MSSH)}

The surface of Mars is seasoned with a variable climate with a decrease in surface temperature below $-73{ }^{\circ} \mathrm{C}$ at night. Hence to maintain stable internal temperature and to provide good thermal insulation, we proposed Mars SubSurface Habitat.

The bottom portion of the habitat has a sub-surface miner which will start to dig the ground up to a certain level to submerge the whole habitat. And the habitat has two hydraulic lifters to move the whole body up and down. The hydraulic legs will lift-up the habitat to the surface during daytime for doing research activities and for the sunlight exposure for temperature regulation including the generation of solar power. Similarly, at night to maintain thermal stability inside the habitat, the hydraulic legs will lift-down the habitat into sub-surface and will get submerged underground.

\section{Mars Solar Power Plant (MSPP)}

Mars Solar Power Plant comprises of eight broad circular solar panels that are enclosed inside a solar array using its foldable arms. Employing this type of solar arrays, we can enclose more number of solar panels inside a single cylindrical module for high electricity generation (especially for the planets that are far away from the sun and have low sunlight intensity).

\section{E. Manual Sub-Surface Ice Drillers}

To keep Martian astronauts engaged, we have proposed this type of manual sub-surface ice drillers to extract water for practical use parallel to the extraction of deposited fossils for laboratory analysis.

\section{F. Mars Crop Culture Module (MCCS)}

We already have a standard MCCS exported from earth aboard Marship and that can be landed safely for planetary farming. Here empty fuel tanks can be customized and engineered on the surface for crop culture (this is an optional approach in case of safe redirection of vacated fuel tanks of both Marships). This empty tanks can be integrated with automated crop maintaining robotics arms exported from Earth for best crop practices. These arms can be installed at the upper portion and the lower portion is for the maintenance of soil and plantation. It also possesses a mechanical gravity simulator powered by electric motors to simulate artificial gravity at the initial stage of the crop growing process. The system has three ports for the flow and exchange of carbon dioxide $\left(\mathrm{CO}_{2}\right)$, oxygen $\left(\mathrm{O}_{2}\right)$, and in-situ water resources $\left(\mathrm{H}_{2} \mathrm{O}\right)$.

\section{G. Atmosphere Regulation System for MCCS}

The atmosphere regulation system has a rectangular carbon-oxygen-hydrogen regulator and three rectangular hollow tanks $\left(\mathrm{CO}_{2}, \mathrm{O}_{2}, \mathrm{H}_{2} \mathrm{O}\right)$. The regulator has three ports: a port to absorb Mars atmospheric $\mathrm{CO}_{2}$ (by monitoring the contamination level and filtering) to store in $\mathrm{CO}_{2}$ tank, a port to absorb water from water tanks deposited by Mars water extraction rover to store within $\mathrm{H}_{2} \mathrm{O}$ tank, and a port for giving out free oxygen for astronauts from $\mathrm{O}_{2}$ storage tank gathered from MCCS.

Similarly, all three tanks have separate port connections from the crop culture system. A port in $\mathrm{CO}_{2}$ tank to supply $\mathrm{CO}_{2}$ to crop culture chamber, an $\mathrm{H}_{2} \mathrm{O}$ port to supply water in a sprinkler distribution method, and finally $\mathrm{O}_{2}$ port to absorb $\mathrm{O}_{2}$ exhausted by the green plants inside MCCS.

\section{H. Solar Cell Radiation Shield (SCRS)}

We have conceptualized to fabricate solar panels with a sufficient thickness of lead material. So that the solar panel can be mounted on top of the habitat thereby protecting and shielding the habitat from cosmic radiation. Because the surface of Mars is exposed to a heavy dose of cosmic radiation from interplanetary space than the surface of our Earth. Hence utilizing this type of solar panel may shield astronauts from harmful cosmic radiation. 

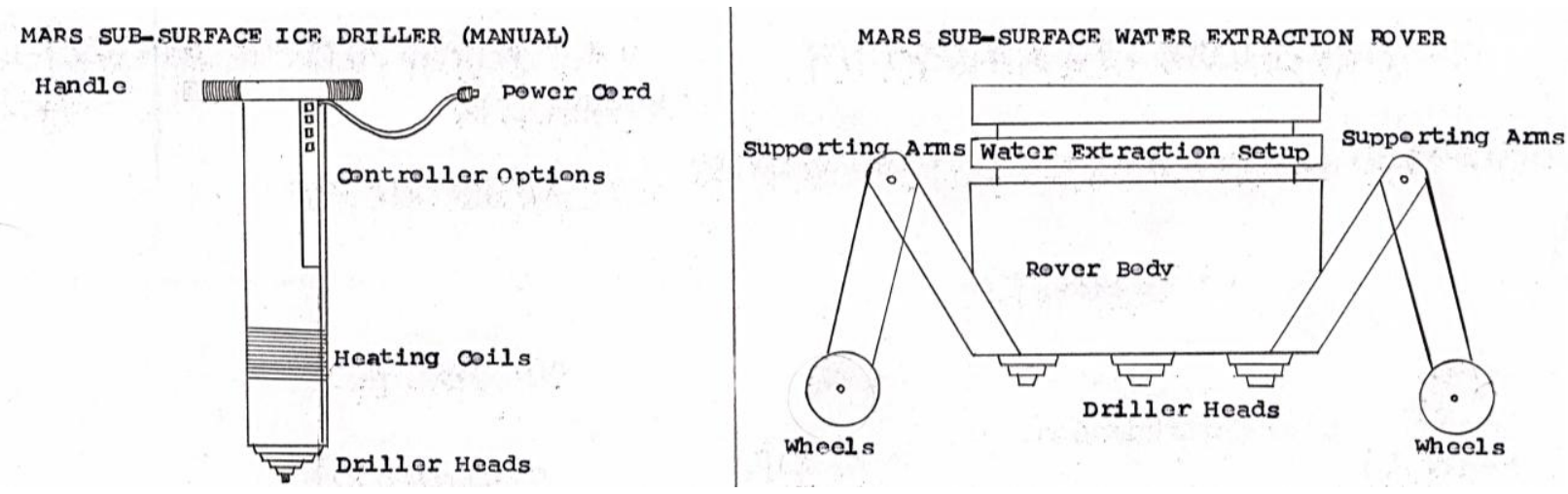

Fig 10 Manual Ice Driller and Water Extraction Rover
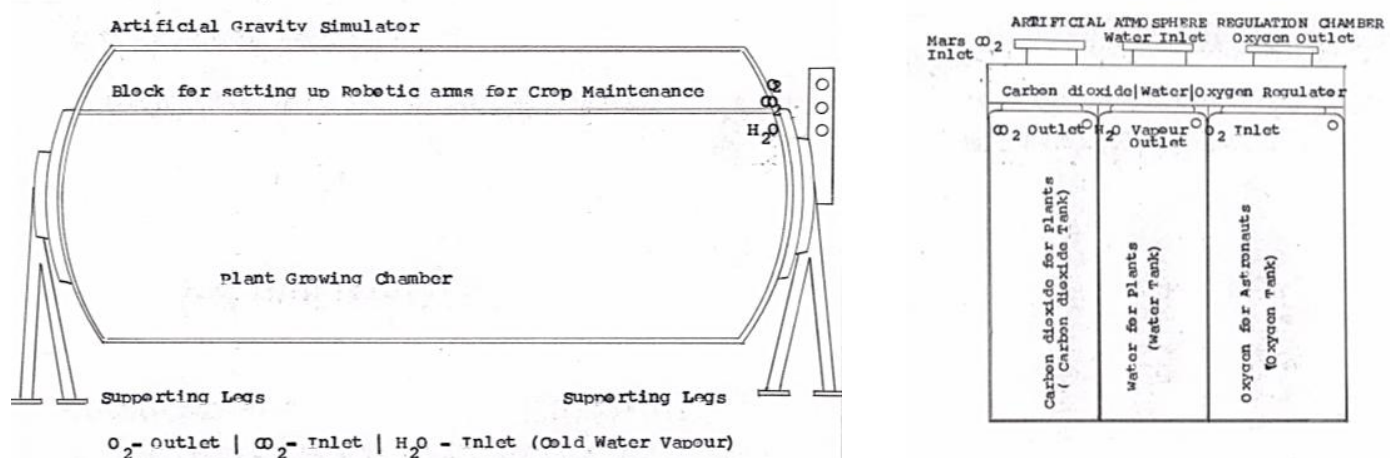

Fig 11 Mars Crop Culture System and its Atmosphere Regulation System
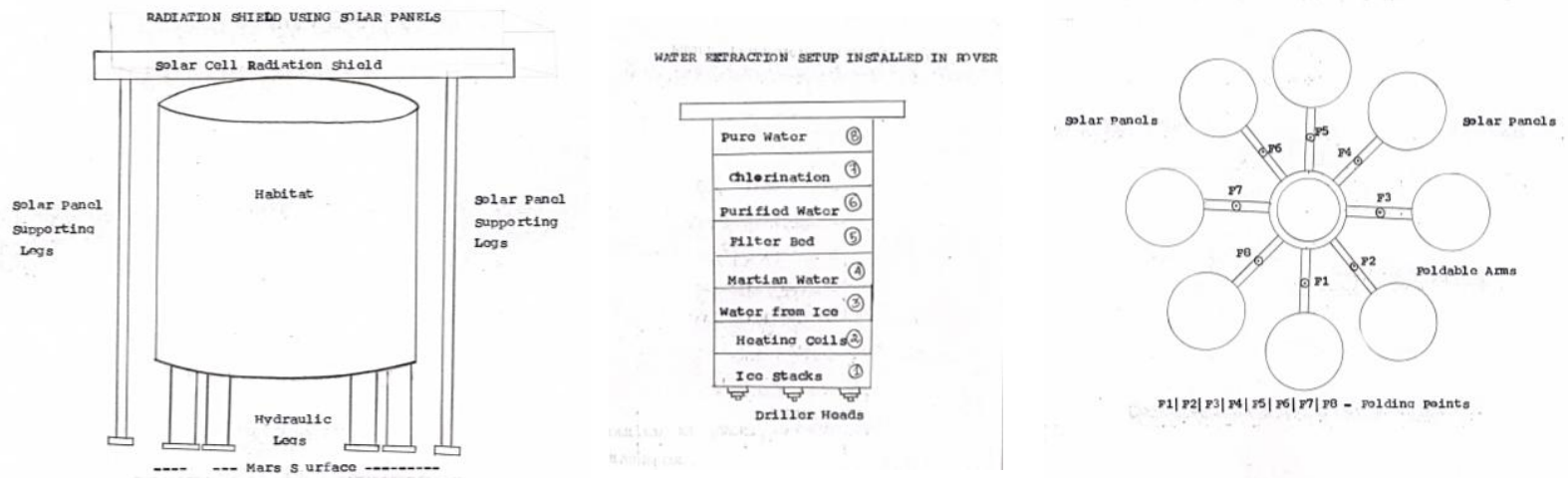

Fig 12 Solar Cell Radiation Shield | Water Extraction Setup (Rover) | Mars Solar Power Plant

\section{Overview of Martian Automobile Technology}

\section{A. Mars Water Extraction Rover}

Mars scientists have discovered sub-surface ice underneath Mars underground. So, it can be exploited in the form of water for numerous surface applications. In addition to manual sub-surface ice drillers, we have commissioned "Water Extraction Rovers" for water extraction. This rover possesses powerful driller heads at the bottom part and the whole rover stands with the aid of four foldable arms. The arms are capable of moving the rover body up and down in a convenient way to carry out the drilling and water extraction process. The rover is enfolded with a water extraction setup to process and transform ice into feasible water. 


\section{Water Extraction Setup from Rover}

The whole setup has eight layers to purify water shown in the block diagram below

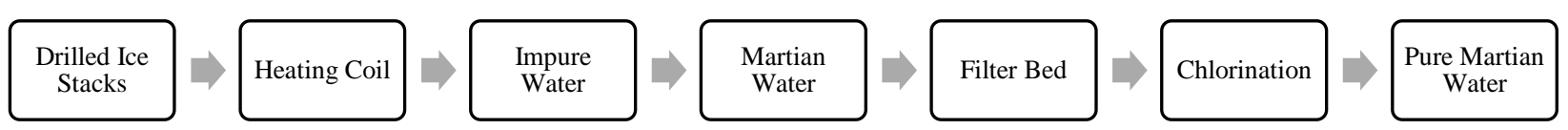

Fig 13 Water Extraction and Purification Process

The driller head at the bottom of the setup will drill and extract ice from the sub-surface. Then it passes through a heating coil powered by solar power, that melts the ice to form impure water. After this process, the impure water gradually gets filtered via filter bed and passed for chlorination. This is followed by purification of water and finally, the water is transformed into consumable drinking water for astronauts and for planting crops. We named the Martian water as "Aqua Mars".

\section{B. Mars Soil Fertilizing Rover}

The Rover is to transform the vast red land soil into fertile soil with the addition of mixtures (human litter with plantation wastes). For this goal accomplishment, the rover will select and map a particular location in square meter in advance and it will move over the tracks.

The process involves the simultaneous intake of unfertile Martian soil and a mixture of wastes through the rover's conveyor belt system. Then the waste is exposed to solar-powered heating to remove the harmful bacteria parallel to the removal of large seized rocks on another side. Then the soil is subjected to the addition of degradable wastes and bio-degradable bacteria to accelerate the degradation process. The soil is kept inside the rover rack for a particular time interval to become fertile. Thereafter, the fertile soil can be directly exposed to the Mars ground or can be used in a planetary farming system.

\section{Mars Load Rover (MLR)}

Mars Load Rover is launched to transport loads from the targeted site to the Mars Base / Mars Colony. The rover is powered by both solar and nuclear thermals to drive fast for rapid development. The mobility of this rover is powered by a conveyor belt for easy maneuver in sandy regions of Mars. The rover can be automatically and manually guided to operate on the surface. It possesses flashlights and night lamps for lighting during night time operations.

\section{Mars Passenger Rover}

Similar to MLR, we have introduced MPR (Mars Passenger Rover) for the mobility with a group of astronauts from their base to access the scientific site or construction site. The operation controls and power systems are the same as MLR. This can be employed in the future for mass movements of Martians from place to place.
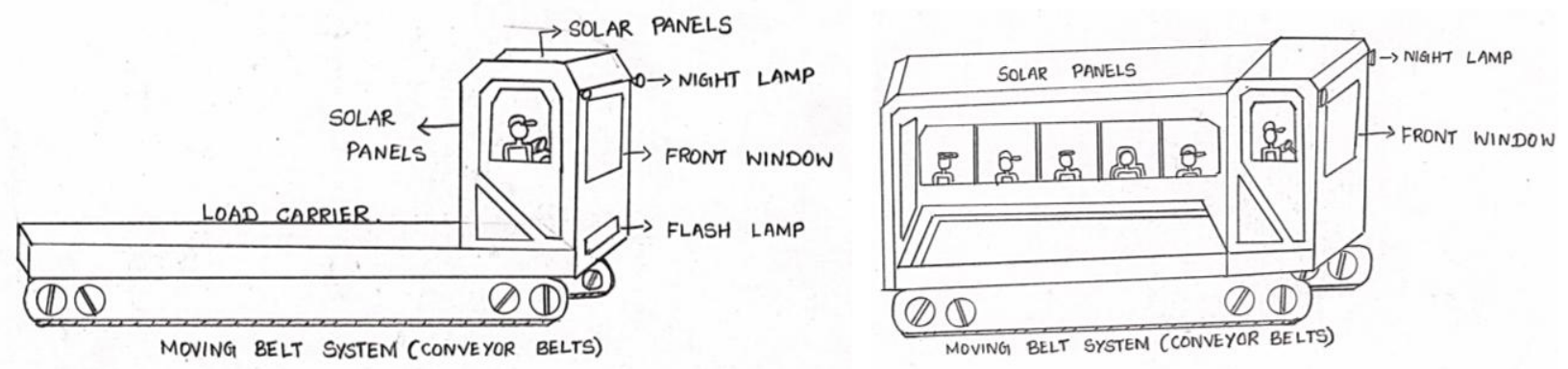

Fig 14 Mars Load Rover (MLR) and Mars Passenger Rover (MPR) 


\section{Mars Production Plants}

\section{A. Rock Sizing Plant}

This plant sizes the rocks and slices into pieces in a standard size for construction applications. The sized rocks are loaded aboard Mars Load Rover to transport it to the construction site. The process involves, upsized rocks or nonuniformed rocks are taken into the plant through a conveyor belt and subjected to sharp surface cutters and polishers. Then sized rocks are passed into slicing sections where the large-sized rock is sliced into optimal size for constructions.

\section{B. Rock Sizing Plant}

The Mars soil is rich in ferrous content and we propose to extract iron from ferrous ores. Iron production involves various processes shown below and finally, the plant produces iron through the smelting process.

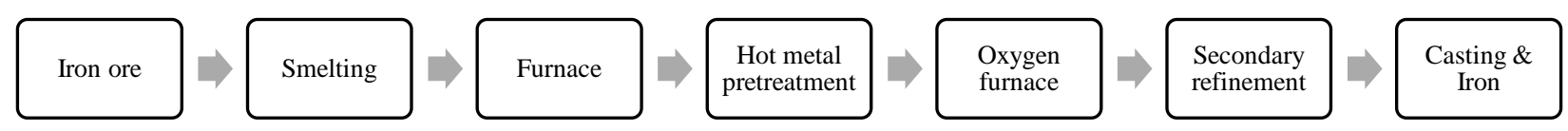

Fig 15 Rock Sizing Process

\section{Mars Propellant Plant}

The in-Situ propellant plant produces propellants for propulsion systems with Mars atmospheric CO2 as their primary sources. And it gets separated into carbon mono-oxide and oxygen. Then it combines with hydrogen (which separated from water through electrolysis method) to form methanol. Propellants are the driving key of launchers, rovers, and operation robots.

\section{Approach to Communication and International Mars Station}

\section{A. A Novel Approach to Communication System}

Communication relay between Earth and Mars is one of the significant challenges for human Mars exploration. So, transmitting signals directly to Mars from the ground (Earth) may not be an efficient approach to stay tethered with lander and rovers. Because it may cause a serious issue during EDL guidance. We know that signals from Earth take an average time lag of 13 to 24 minutes to outreach Mars and the shortest time lag ever achieved is 8 minutes through a communication session with NASA's Curiosity Rover (MSL). In addition to this, during the occurrence of blackouts due to solar conjunctions for about 15 days for every 26 months may cause critical concern in signal transmission. Therefore, for effectuating better communication sessions during EDL phases, we proposed an advanced communication relay from Earth to Mars through the following.

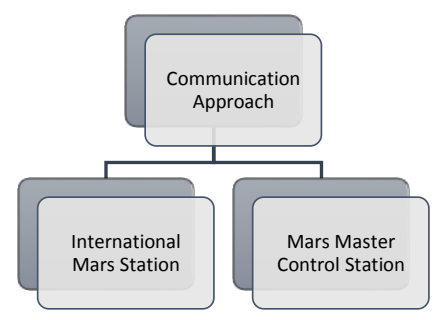

\section{Fig 16 Different Ways of Communication Approach}

Both systems are capable of receiving and amplifying the command signals from the ground and intelligently proofreading. Similarly, it is capable of rectifying the erroneous signals incautiously transmitted by the ground controllers. It is possible because all the mission plans and programs were submitted in advance to these systems (IMS $\&$ MMCS) by the mission experts. 


\section{B. Salient Features of IMS}

International Mars Station is automated in absence of astronauts and manual in the presence. The structure of IMS is most similar to ISS. IMS extends its hospitality services for astronauts and provides a better place for desiring and planning. IMS is managed and maintained by the Martians. IMS will be considered as one of the significant platforms for easy access to Mars and beyond.

\section{Salient features of MMCS}

Mars Master Control Station is a distinctive probe completely dedicated to signal processing, signal amplification, and signal proofreading. The probe is specially designed with dual computer and communication systems for sustained operation during systems or communication failure. Hence, we have planned to place it in either Mars orbit or planting it on any of the two Martian natural satellites (Phobos \& Deimos). Further, the MMCS is fully automated with advanced computer processing systems.

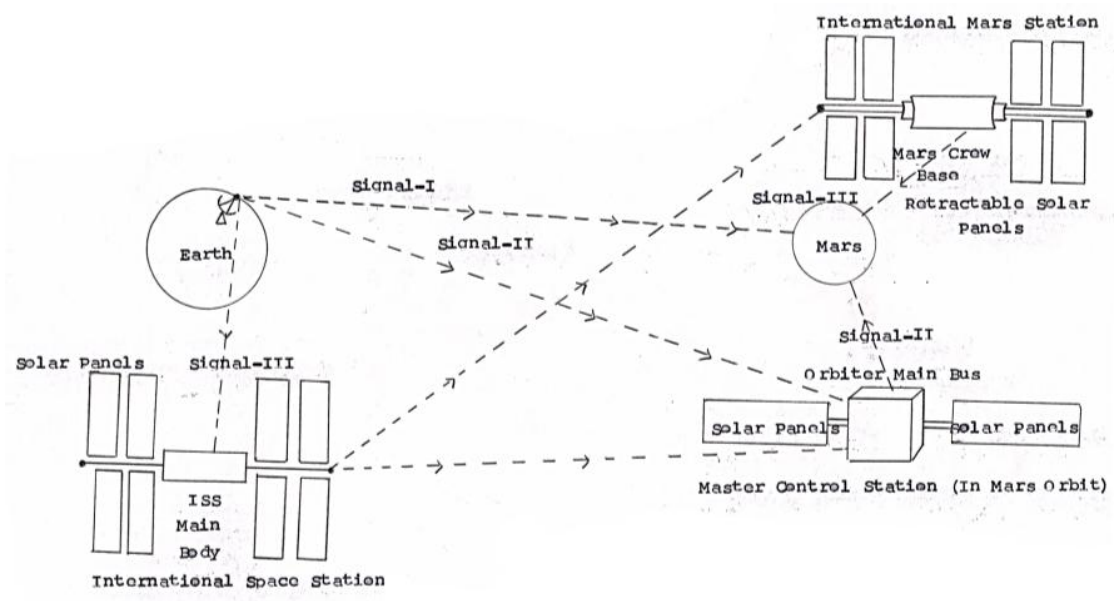

Fig 17 Earth - Mars Communication System

\section{Mars Minerals, Space Plants and Mars Activities}

\section{A. Mars Minerals}

The composition of Mars has a diversity of mineral resources tabulated below. Based on the ease of accessibility and extraction, we can set up numerous fabrication plants on the planetary surface. Some of the accessible minerals and their applications listed below.

Table 1 Mars Minerals and their Applications

\begin{tabular}{|l|l|l|}
\hline S.No & Minerals & Applications \\
\hline 01. & Olivine & Refractory Materials \\
\hline 02. & Marcasite & Diamond and Graphite \\
\hline 03. & Feldspar & Dinnerware, Bathroom, and building tiles, Glass production, Flux \\
\hline 04. & Ilmenite & Aircraft parts, Titanium metal, Reflective pigments, Synthetic rutile \\
\hline 05. & Akaganeite & Adsorption of arsenic to prevent pollution \\
\hline 06. & Hematite & Storage Devices, Electrical components, Inorganic pigments \\
\hline 07. & Magnetite & Water purification, Biomedical, and environmental applications \\
\hline 08. & Goethite & Cleaning chemical elements in polluted water \\
\hline 09. & Saponite & Water Decontamination, Rubber, Cosmetics, and Medicine \\
\hline 10. & Montmorillonite & Nuclear applications, Cotton fiber, Adsorption in heavy metals and dyes \\
\hline 11. & Serpentinite & Architecture, Ornaments, Asbestos \\
\hline 12. & Illite & Ceramics, Tiles \\
\hline 13. & Keiserite & Cleaning hard water, Epsom salt, Fertilizer \\
\hline 14. & Gypsum & Cement, Plaster of Paris \\
\hline
\end{tabular}




\section{B. Space Plants for In-Space Farming}

Space farming is very significant for astronaut's survival. They are always depending and interlinked with each other. Hence we have recommended some of the food production plants to meet food requirements, research plants to carry out life experiments, ornamental plants for spaceship/Mars Base interior decoration, and finally oxygenproducing plants for the enhancement of carbon-oxygen gases between plants and astronauts. We have tabulated some of the space plants.

Table 2 List of Space Plants

\begin{tabular}{|l|l|l|l|l|}
\hline S.No & Food Production Plants & Research Plants & Ornamental Plants & Oxygen Producing Plants \\
\hline 01. & Arugula & Arabidopsis thaliana & Zinnia & Area Palm \\
\hline 02. & Spinach & Brachypodium distachyon & & Snake Plant \\
\hline 03. & Carrots & Brassica rapa & & Money Plant \\
\hline 04. & Cucumbers & Ceratopteris richardii & & Gerbera Daisy \\
\hline 05. & Beet Roots & Mizuna Lettuce & & \\
\hline 06. & Bush Beans & Zucchini & & \\
\hline 07. & Bok Choy & Wheat & & \\
\hline 08. & Lettuce & Red Romaine Lettuce & & \\
\hline 09. & Summer Squash & Rice & & \\
\hline 10. & Okra & Tomato & & \\
\hline 11. & Kale/Greens & Spinach & & \\
\hline 12. & Snow Peas & Pepper & & \\
\hline 13. & Broccoli & Broccoli & & \\
\hline 14. & Green Onions & & & \\
\hline 15. & Turnips & & & \\
\hline 16. & Radishes & & & \\
\hline
\end{tabular}

\section{Education (Mars Institute of Space Sciences)}

Mars Institute of Space Sciences should train and teach the Martians about the following subjects: Stellar, Solar Galactic, Extragalactic astronomy, planetary science, physical cosmology, Astrochemistry, Astrobiology, Astrophysics, aerospace, Space plasma physics, orbital mechanics, astrodynamics, atmospheric/environmental sciences, satellite and space communications, space systems, space environment, and space medicine.

In addition to this, we should train them on the following: How to do space farming? how to avoid space accidents? How to survive in a critical space environment utilizing in-situ resources? How to manage space activities? Briefing and explaining about the space science; explaining our ancestors and where we came from.

\section{Sport Activities}

Sports activities include running and jogging, gravity-related games, skipping and jumping games, regular practice of breathing games, surviving challenge games in favor of Mars survival challenge, and miscellaneous. So that they can tackle every critical circumstance.

\section{Conclusion}

In this paper, we have discussed a baseline mission strategy for the development of human Mars mission architecture. The diagrams and figures depicted in this paper are not scalable and are indigenously collected from our previous preprint entitled "Human Mars Mission Architecture" in reference [1]. And also a revised version of that paper with additional description. The paper is being prepared for providing an outline for further studies and development of technologies for Human Mars expedition. The content of this paper is authentic and is the result of my past paper experiences and have not taken from any other copyrighted materials. 


\section{Acknowledgments}

The main author Malaya Kumar Biswal M would like to dedicate this work to his beloved mother late. Mrs. Malathi Biswal for her motivational speech and emotional support throughout his life.

The authors would like to extend their sincere thanks to S Mohit and M Soundharrya for having a group discussion and have shown us the perspective to formulate some concepts.

The authors would like to extend their since thanks and gratitude to Dr. Robert Zubrin (CEO of the Mars Society) for announcing the Design of Human Mars Settlement Contest during the year 2019. The contest has shown a wonderful way to write this paper.

\section{Appendices}

\section{International Mars Station}

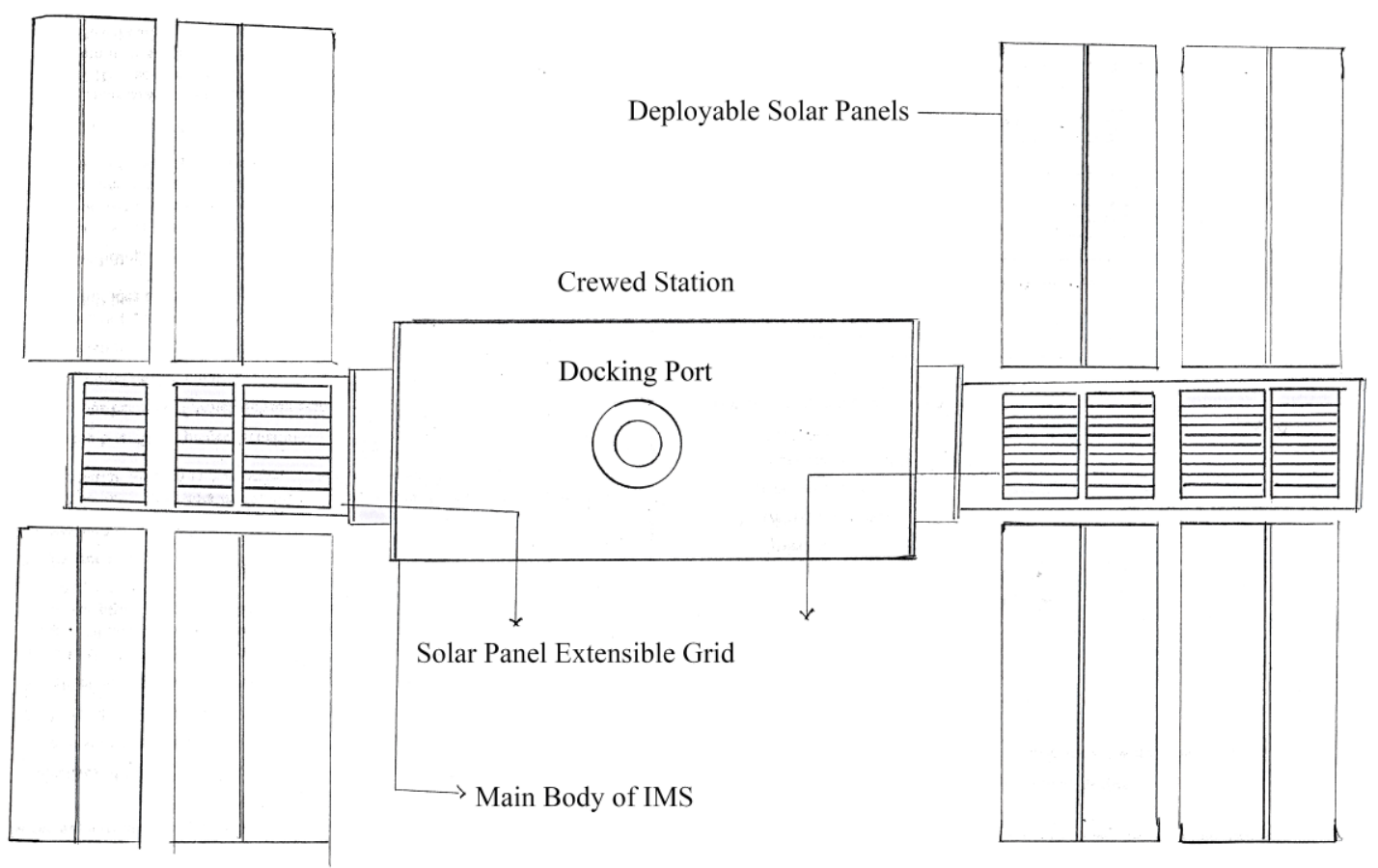

Fig 19 Blue print of International Mars Station

Logo of Contributior: SpaceXpress Space Initiative, India - 2020

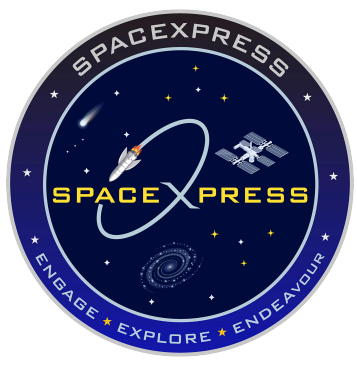




\section{References}

[1] Biswal M, Malaya Kumar \& Vs, Vishnu \& Kumar, Devika \& Murugavel, Sairam. (2019). Human Mars Mission Architecture -- Plan to Settle the Red Planet with 1000 People.

[2] Kumar, D. S. (2019). Human Mars Mission Architecture--Plan to Settle the Red Planet with 1000 People. arXiv preprint arXiv:1904.01389.

[3] Biswal M, Malaya Kumar \& Annavarapu, Ramesh Naidu. (2018). A Novel Entry, Descent and Landing Architecture for Mars Landers.

[4] Biswal M, Malaya Kumar \& Annavarapu, Ramesh Naidu. (2019). Mars Missions Failure Report Assortment : Review and Conspectus.

[5] Etherington, D. (2019). Spacex Details Starship and Super Heavy in New Website.

[6] Hughes, S., Cheatwood, F., Dillman, R., Calomino, A., Wright, H., DelCorso, J., \& Calomino, A. (2011, May). Hypersonic inflatable aerodynamic decelerator (hiad) technology development overview. In 21st AIAA Aerodynamic Decelerator Systems Technology Conference and Seminar (p. 2524).

[7] Zubrin, R. M., Muscatello, A. C., \& Berggren, M. (2013). Integrated Mars in situ propellant production system. Journal of Aerospace Engineering, 26(1), 43-56.

[8] Costard, F., Forget, F., Mangold, N., \& Peulvast, J. P. (2002). Formation of recent Martian debris flows by melting of near-surface ground ice at high obliquity. Science, 295(5552), 110-113.

[9] Catchpole, J. E. (2008). The international space station: building for the future. Springer Science \& Business Media.

[10] D. Edwards, C. (2007). Relay communications for Mars exploration. International Journal of Satellite Communications and Networking, 25(2), 111-145.

[11] Millour, E., Forget, F., Spiga, A., Navarro, T., Madeleine, J. B., Montabone, L., ... \& Lopez-Valverde, M. A. (2015, September). The Mars climate database (MCD version 5.2). In European Planetary Science Congress (Vol. 10, pp. 2015-2438).

[12] Bibring, J. P., Langevin, Y., Gendrin, A., Gondet, B., Poulet, F., Berthé, M., ... \& Drossart, P. (2005). Mars surface diversity as revealed by the OMEGA/Mars Express observations. Science, 307(5715), 1576-1581.

[13] Singer, R. B., McCord, T. B., Clark, R. N., Adams, J. B., \& Huguenin, R. L. (1979). Mars surface composition from reflectance spectroscopy: A summary. Journal of Geophysical Research: Solid Earth, 84(B14), 8415-8426.

[14] Halstead, T. W., \& Dutcher, F. R. (1987). Plants in space. Annual review of plant physiology, 38(1), 317-345. 